NBER WORKING PAPER SERIES

\title{
ACTIVIST MONETARY POLICY, IMPERFECT \\ CAPITAL MOBILTY, AND THE \\ OVERSHOOTING HYPOTHESIS
}

Daviã H. Papell

Working Paper No. 1244

\author{
NATIONAL BUREAU OF ECONOMIC RESEARCH \\ 1050 Massachusetts Avenue \\ Cambridge, MA 02138 \\ December 1983
}

I am grateful to Eleanor Brown, Larry Christiano, John Huizinga, Howard Kaufold, and to participants at seminars at the University of Florida, the University of Pennsylvania, the International Finance Division of the Federal Reserve Board, and the 1983 Econometric Society Summer Meetings for their comments. The research reported here is part of the NBER's research program in International Stuaies. Any opinions expressed are those of the author and not those of the National Bureau of Economic Research. 


\section{ACTIVIST MONETARY POLICY, IMPERFECT CAPITAL}

MOBILITY, AND THE OVERSHOOTING HYPOTHESIS

\section{ABSTRACT}

The hypothesis of exchange rate overshooting is investigated in the context of a model that incorporates activist monetary policy, variable output, imperfect capital mobility, and slow price adjustment. Monetary policy which accommodates prices and/or interest rates is shown to increase the likelihood of undershooting. Using constrained maximum likelihood methods, the model is estimated for Germany and Japan since the advent of generalized floating in 1973. Based on the estimated parameter values, the mark exhibits overshooting while the yen is characterized by undershooting. The constraints implied by the model cannot (by likelihood ratio tests) be rejected at standard significance levels for either country.

David H. Papell

Department of Economics

University of Florida

Gainesville, FL 32611

(904) 392-2999 


\section{Introduction}

After a decade of experience with flexible exchange rates, it is clear that exchange rate variability exceeds national price level variability. The resultant variability of the "real" exchange rate has had important macroeconomic ramifications during the 1970 's. These ramifications, often considered adverse by governments, have led some analysts to reconsider their support for flexible exchange rates and/or to advocate increased intervention in the foreign exchange market.

The best known explanation for high exchange rate vâriability is Dornbusch's (1976) overshooting hypothesis. According to this hypothesis, when (for example) the money supply permanently increases, the exchange rate will first depreciate by more than its long run depreciation, and then appreciate back to the steady state. In contrast, undershooting occurs when, following the money supply increase, the exchange rate first depreciates by less than its long run depreciation, followed by further depreciation until the steady state is attained.

This paper considers three reasons why, in an economy which would otherwise be characterized by overshooting, undershooting may occur: imperfect capital mobility, variable output, and activist monetary policy. The analysis builds on previous work, especially Frenkel and Rodriguez (1982), who show that sufficiently imperfect capital mobility can cause exchange rate undershooting, Dornbusch (1976), who shows that overshooting is not necessary if output is variable, Papell (1982), who demonstrates that monetary policy which accommodates prices can cause undershooting, and Frenkel (1983), who advocates using monetary policy to target both interest rates and exchange rates. The paper shows, both theoretically and empirically, how these factors combine to produce over-or undershooting. 
The model is then estimated for Germany and Japan, using quarterly data from 1973-1981. The major finding is that, based on the estimated parameter values, the Deutsche Mark exhibits overshooting while the yen is characterized by undershooting. The model is estimated by constrained maximum likelihood methods, with the constraints caused by the form of the structural equations and assumption of rational expectations. It is noteworthy that, using likelihood ratio tests, the constraints cannot be rejected at standard significance levels for either country. This is far more empirical support than can generally be claimed for open economy macroeconomic models using data from the 1970's.

The paper is organized as follows. The model is presented in Section II. Imperfect capital mobility, variable output, and activist monetary policy are shown to combine to produce over- or undershooting in Section III and the model is estimated in Section IV. Conclusions and extensions are presented in Section $V$.

II. The Model

The model is based on Dornbusch (1976), although it differs from his work in a number of respects. It is a two-country model, incorporating variable output and imperfect capital mobility, in which the domestic and foreign money supplies are determined endogenously. The two country specification, rather than a single, small country specification, was chosen for two reasons. First, the small country specification requires making exogeneity assumptions regarding foreign prices and interest rates which cannot be supported empirically. ${ }^{1}$ Second, the two country specification allows for the foreign money supply, as well as the domestic money supply, to be determined endogenously. This is shown below to be quite important, both theoretically and empirically, regarding the existence of 
overshooting. The model consists of the following equations.

(1) $m_{t}-m_{t}^{*}-q_{t}=a_{1}\left(y_{t}-y_{t}^{*}\right)-a_{2}\left(i_{t}-i_{t}^{*}\right)+\varepsilon_{1 t}$

(2) $y_{t}-y_{t}^{*}=\left(y_{0}-y_{0}^{*}\right)+a_{3}\left(e_{t}-q_{t}\right)-a_{4}\left(r_{t}-r_{t}^{*}\right)+\varepsilon_{2 t}$

(3) $i_{t}-i_{t}^{*}=\left(\hat{e}_{t+1}-e_{t}\right)-a_{5}\left(\tilde{e}_{t}-\tilde{q}_{t}\right)+\varepsilon_{3 t}$

(4) $q_{t+1}-q_{t}=a_{6}\left(e_{t}-q_{t}\right)-a_{7}\left(r_{t}-r_{t}^{*}\right)+\varepsilon_{4 t}$

(5) $m_{t}=m_{0}+a_{8} \tilde{e}_{t}+a_{9} \tilde{q}_{t}+a_{10}\left(i_{t}-i_{t}^{*}\right)+\varepsilon_{5 t}$

(6) $m_{t}^{*}=m_{0}^{*}-a_{11} \tilde{e}_{t}-a_{12} \tilde{q}_{t}-a_{13}\left(i_{t}-i_{t}^{*}\right)+\varepsilon_{6 t}$

where $m$ is the logarithm of the domestic money supply,

$y$ is the logarithm of domestic real output,

$i$ is the domestic nominal interest rate,

$r$ is the domestic real interest rate,

e is the logarithm of the exchange rate (domestic currency price of foreign exchange),

* associated with a variable indicates that it refers to the foreign country,

$q$ is the logarithm of the ratio of domestic to foreign prices, $i . e ., q_{t}=p_{t}-p_{t}^{*}$ where $p$ is the logarithm of the domestic prtce lével,

$\sim$ over a variable indicates deviation from the steady state
level,

$y_{0}$ is the exogenous component of output,

$m_{0}$ is the exogenous component of the money supply,

$\hat{e}_{t+1}$ is the expectation of the exchange rate for period $t+1$, conditional on information available in period $t$,

the $\varepsilon^{\prime} s$ are random variables, which may be serially correlated.

The specifications of the asset markets are conventional. Supply and

demand for real balances for each country are equated in equilibrium, and the demand for money depends positively on income and negatively on the interest rate. 2

(1a) $m_{t}-p_{t}=a_{1} y_{t}-a_{2} j_{t}+n_{1 t}$ 
(1b) $m_{t}^{*}-p_{t}^{*}=a_{1} y_{t}^{*}-a_{2} i_{t}^{*}+n_{2 t}$

Equation (1) is obtained by subtracting (1b) from (1a) and defining $\varepsilon_{1 t}=$ $n_{1 t}-n_{2 t}$. The income elasticities and interest rate semi-elasticities of the two countries need to be equated for the model to be tractable. This is the principal drawback to using the two-country model. 3

Real output in each country depends on the relative price of domestic and foreign goods, the real interest rate, an exogenous term and a stochastic disturbance term. If the relative price of foreign goods is high, $\left(e_{t}\right.$ $>q_{t}$, i.e., $\left.e_{t}+p_{t}^{*}>p_{t}\right)$, domestic output is above and foreign output is below the values that would be attained under instantaneous purchasing power parity. While deviations from purchasing power parity are allowed in the short run, it is assumed that long run purchasing power parity holds $(\overline{\mathrm{e}}=\overline{\mathrm{q}})$.

(2a) $y_{t}=y_{0}+b_{2}\left(e_{t}-q_{t}\right)-a_{4} r_{t}+n_{3 t}$

(2b) $y_{t}^{*}=y_{0}^{*}-b_{3}\left(e_{t}-q_{t}\right)-a_{4} r_{t}^{*}+n_{4 t}$

Equation (2) is obtained by setting $a_{3}=b_{2}+b_{3}, \varepsilon_{2 t}=n_{3 t}-n_{4 t}$, and by subtraction. 4

If capital were perfectly mobile, the domestic interest rate would equal the foreign interest rate plus the expected rate of depreciation. In order to incorporate imperfect capital mobility into our analysis, we adopt the specification used by Frenkel and Rodriguez (1982). The current account balance is assumed to depend on the relative price of domestic and foreign goods.

(3a) $T_{t}=b_{4}\left(\tilde{e}_{t}-\tilde{q}_{t}\right)+n_{5 t}$,

where $T_{t}$ is the current account surplus (not in logarithms). Capital flows are assumed to depend on the difference between rates of return on securities denominated in the two currencies (net of expected exchange rate 
depreciation),

(3b) $c_{t}=b_{5}\left(i_{t}-i_{t}^{*}-\left(\hat{e}_{t+1}-e_{t}\right)\right)+n_{6 t}$,

where $C_{t}$ is the capital account surplus (not in logarithms). In the absence of Central Bank intervention, balance of payments equilibrium requires that the sum of the current and capital account surpluses equal zero. This is represented in equation (3), with $a_{5}=b_{4} / b_{5}$ and $\varepsilon_{3 t}=$ $-\left(n_{5 t}+n_{6 t}\right) / b_{5}$. Notice that if capital were perfectly mobile, $b_{5}=\infty$ implies that $a_{5}=\varepsilon_{3}=0.5$

As in Dornbusch (1976), the rate of inflation in each country is assumed to depend on excess demand in the goods market, 6

(4a) $p_{t+1}-p_{t}=b_{7}\left(y_{t}-\bar{y}\right)+n_{7 t}$

(4b) $p_{t+1}^{*}-p_{t}^{*}=b_{8}\left(y_{t}^{*}-\bar{y}^{*}\right)+n_{8 t}$

where $\bar{y}=y_{0}-a_{4} \bar{r}$ and $\bar{y}^{\star}=y_{0}^{\star}-a_{4} \bar{r}^{\star}$ are the steady state levels of output. The steady state real interest rates, $\bar{r}$ and $\bar{r}^{*}$, are equal because the long run equilibrium is assumed to be characterized by constant exchange rates and prices. The assumption of purchasing power parity then implies uncovered interest rate parity, which in turn causes nominal interest rates to be equated. Real interest rates are then equated by the Fisher relation.

Substituting $(2 a, b)$ into $(4 a, b)$, and subtracting $(4 b)$ from $(4 a)$, we obtain equation (4), where $a_{6}=b_{2} b_{7}+b_{3} b_{8}, a_{7}=b_{7} a_{4}=b_{8} a_{4}$, and $\varepsilon_{4 t}=b_{7} n_{3 t}+n_{7 t}-b_{8} n_{4 t}-n_{8 t}$. Note that we have imposed the constraint that $b_{7}=b_{8}$, which is necessary because the real interest rate enters equation (4) in difference form, on $a_{7}$ but not on $a_{6}$. If applied consistently, equation (4) would read, (4c) $q_{t+1}-q_{t}=b_{7} a_{3}\left(e_{t}-q_{t}\right)-b_{7} a_{4}\left(r_{t}-r_{t}^{*}\right)+\varepsilon_{4 t}$. When the model was estimated with this constraint, it was clearly rejected 
in favor of the model reported in the text. We felt that the misspecification from the unsupported constraint was worse than the inconsistency in the less constrainted model. It should also be noted that both domestic and foreign prices are pre-determined. 7

The money supply for each country depends on the exchange rate, the difference between domestic and foreign prices, and the interest rate differential. 8 If the exchange rate depreciates (increases), the domestic money supply is accommodative if $a_{8}>0$, offsetting if $a_{8}<0$. Thus, an offsetting rule would decrease the money supply in response to a depreciation in order to cause the exchange rate to appreciate. For the foreign country, since a depreciation is a decrease in $e$, an accommodative rule consists of $a_{11}>0$, an offsetting rule of $a_{11}<0$. Mussa (1981b) argues that the behavior of exchange rates has influenced the conduct of monetary policy of a number of countries since generalized floating began in 1973 .

If the logarithm of the ratio of domestic to foreign prices increases monetary policy is accommodative if $a_{9}$ and/or $a_{12}>0$, offsetting if $a_{9}$ and/or $a_{12}<0.9$ The money supply is constrained to respond to the price ratio, rather than to the levels separately, because, in the reduced form of the model, prices appear only in ratio form. While allowing the money supplies to respond separately to domestic and foreign levels would be desirable, it would make the model analytically intractable. 10 Taylor (1980), using annual data for the period 1955-1978, provides econometric evidence that the money supply accommodated the domestic price level for a number of countries. The money supply could have been postulated to respond directly to output movements without affecting the theoretical results. This involves having the money supply respond to movements of the real exchange rate, instead of to the exchange rate and price ratio sepa- 
rately, and would constrain $a_{8}=-a_{9}$ and $a_{11}=-a_{12}$. In this sense, monetary policy that offsets exchange rate movements and accommodates price movements can be interpreted as attempting to stabilize output.

Frenkel (1983) has recently proposed that, if the monetary authorities wish to stabilize the exchange rate, they should have the money supply respond to the interest rate as well as to the level of the exchange rate. He suggests that, if there is a combination of a high nominal interest rate differential and a depreciation of the currency, the money supply should not be increased but, if there is a combination of a high nominal interest rate differential and an appreciation of the currency, then expansionary monetary policy is appropriate. This argument is based on the grounds that the interest rate contains additional information that is useful for exchange rate stabilization.

In the context of our model, we interpret Frenkel's proposal by allowing the domestic and foreign money supplies to respond to the interest rate differential. This allows the monetary authorities to use information regarding the expected rate of depreciation (from equation (3)) that is not contained in the exchange rate or price level. A policy of accommodating interest rate differentials requires $a_{10}$ and/or $a_{13}>0$; offsetting them implies $a_{10}$ and/or $a_{13}<0$. For example, if the domestic interest rate increased relative to the foreign rate and $a_{10}>0$, the domestic money supply would increase, requiring, by equation (1), the domestic rate to decrease relative to the foreign rate to maintain asset market equilibrium. Finally, the money supply rule for each country includes an exogenous term and a stochastic disturbance term.

Frenkel's proposal can be implemented by offsetting the exchange rate and accommodating the interest rate differential in a particular manner. 
When the nominal interest rate differential is positive and the exchange rate appreciates, this policy increases the money supply whatever the magnitudes of the coefficients. On the other hand, the combination of a positive nominal interest rate differential and a depreciation of the currency requires that the coefficient on the exchange rate $\left(a_{8}\right)$ be large enough (in absolute value) so that the money supply does not increase. It is interesting to note that this policy cannot be implemented solely by targeting the exchange rate or the interest rate differential. Accommodating a positive interest rate differential will increase the money supply regardless of the value of the exchange rate. Offsetting the exchange rate, without targeting the interest rate, implies that the money supply will decrease in response to a depreciation. With a positive interest rate differential, the combination policy will mitigate this decrease, producing the desired result.

It is illustrative to compare this model to earlier work. If both output and the domestic and foreign money supplies are exogenous, the resultant model is that of Frenkel and Rodriguez (1982). If, in addition, capital is perfectly mobile $\left(a_{5}=0\right)$, the model becomes that of Dornbusch (1976). Dornbusch's variable output case can be produced by allowing output to be endogenous as in equation (2). It aiso should be noted that, in both Dornbusch (1976) and Frenkel and Rodriguez (1982) inflation depends only on excess demand in the goods market $\left(a_{7}=0\right)$. This, however, does not affect the conditions for over- and undershooting.

III. Theoretical Results: Overshooting and Undershooting

In this section, we show how variable output, imperfect capital mobility, and monetary policy that accommodates price and/or offsets interest rate movements can combine to produce exchange rate undershooting. 
Since any of the above three factors alone can produce undershooting, the focus of this section is to show their effects in conjunction with one another.

The clearest way to derive and illustrate these results is through a deterministic specification with perfect foresight expectations. Assuming that expectations are perfect foresight, setting the disturbances equal to zero, and substituting equation (3) into (5) and (6), we obtain:

$$
\begin{aligned}
& m_{t}=m_{0}+c_{1} \tilde{e}_{t}+c_{2} \tilde{q}_{t}+a_{10}\left(\hat{e}_{t+1}-e_{t}\right) \\
& m_{t}^{*}=m_{0}^{*}-c_{3} \tilde{e}_{t}-c_{4} \tilde{q}_{t}-a_{13}\left(\hat{e}_{t+1}-e_{t}\right) \\
& \text { where } c_{1}=a_{8}-a_{5} a_{10} \\
& c_{2}=a_{9}+a_{5} a_{10} \\
& c_{3}=a_{11}-a_{5} a_{13} \\
& c_{5}=a_{12}+a_{5} a_{13}
\end{aligned}
$$

Some of the effects of using interest rate targets for monetary policy can be seen directly from (7). If the money supply accommodates the interest rate differential, $\left(a_{10}, a_{13}>0\right)$, then monetary policy becomes more offsetting towards the exchange rate but more accommodative towards prices. The magnitude of these effects also depends on the degree of capital mobility. If capital were perfectly mobile $\left(a_{5}=0\right)$, interest rate targeting would not affect the degree of accommodation.

It will prove useful to simplify the price equation. Assuming the Fisher relation for each country, where the real interest rate equals the nominal interest rate minus the expected rate of inflation, remembering that prices are predetermined, and substituting (3) into (4), we obtain: (4') $q_{t+1}-q_{t}=d_{1}\left(e_{t}-q_{t}\right)-d_{2}\left(\hat{e}_{t+1}-e_{t}\right)$, where $d_{1}=\left(a_{6}+\left(a_{5} a_{7}\right)\right) /\left(1-a_{7}\right)$ and $d_{2}=a_{7} /\left(1-a_{7}\right)$. Substituting (3) and ( $4^{\prime}$ ) into (2) and using the Fisher relation; the output equation becomes, $\left(2^{\prime}\right) y_{t}-y_{t}^{*}=\left(y_{0}-y_{0}^{*}\right)+d_{3}\left(e_{t}-q_{t}\right)-d_{4}\left(\hat{e}_{t+1}-e_{t}\right)$, 
where $d_{3}=a_{3}+a_{4}\left(a_{5}+d_{1}\right)$ and $d_{4}=a_{4}\left(1+d_{2}\right)$.

Substituting $\left(2^{\prime}\right),(3)$, and (7) into (1), taking deviations from steady state equilibrium, and substituting into (4'), we obtain

$$
\left[\begin{array}{l}
D e_{t} \\
D q_{t}
\end{array}\right]=\left[\begin{array}{ll}
\delta_{1} & \delta_{2} \\
\delta_{3} & \delta_{4}
\end{array}\right]\left[\begin{array}{l}
e_{t}-\bar{e} \\
q_{t}-\bar{q}
\end{array}\right]
$$

where $D$ is the forward difference operator, i.e., $D x_{t}=x_{t+1}-x_{t}$ for $x=$ $(e, q)$, and,

$$
\begin{array}{ll}
\delta_{1}=\frac{a_{1} d_{3}+a_{2} a_{5}-c_{1}-c_{3}}{a_{4}+a_{10}+a_{13}+a_{1} d_{4}} & \delta_{2}=\frac{1-a_{1} d_{3}-a_{2} a_{5}-c_{2}-c_{4}}{a_{2}+a_{10}+a_{13}+a_{1} d_{4}} \\
\delta_{3}=d_{1}-d_{2} \delta_{1} & \delta_{4}=-\left(d_{1}+d_{2} \delta_{2}\right) .
\end{array}
$$

In order to illustrate the cases of over- and undershooting, we will assume that the money supply either offsets or is not too accommodative of exchange rate movements, so that $\delta_{1}>0 .{ }^{11}$ We also assume, for the purpose of illustration, that $\delta_{3}>0$ and $\delta_{4}<0$ so that the slope of the $D q_{t}=0$ curve is positive. ${ }^{12}$ The behavior of the model is now determined by the income $\left(a_{1}\right)$ elasticity and the interest rate $\left(a_{2}\right)$ semi-elasticity of the demand for money, the elasticity of demand for output with respect to relative prices $\left(d_{3}\right)$, the degree of capital mobility $\left(a_{5}\right)$, and the degree of accommodation of domestic $\left(c_{2}\right)$ and foreign $\left(c_{4}\right)$ monetary policy to price movements.

Exchange rate oversnooting is illustrated in Figure 1.13 If output is not too variable, capital not too immobile, and/or policy not too accommodative, $\delta_{2}>0$. With both $\delta_{1}$ and $\delta_{2}>0$, the slope of the $D e_{t}=0$ schedule is negative. An unanticipated, permanent increase in the exogenous component of the domestic money supply, starting from a position of long run 
equilibrium (E), shifts the $D e_{t}=0$ and the $D q_{t}=0$ schedules to the right. (To simplify the figures, the schedules are drawn only after the disturbance occurs.) The motion of the variables is indicated by the direction of the arrows. The unique perfect foresight equilibrium path, the saddle path, is downward sloping. At the time of the disturbance, the price level, being predetermined, is fixed. The exchange rate must jump (depreciate) to $E^{1}$ so as to be on the new saddle path, and then appreciate along the saddle path towards the new long run equilibrium $E^{2}$. Long run purchasing power parity ensures that $e_{t}=q_{t}$ at both the initial (E) and final $\left(E^{2}\right)$ equilibria.

Exchange rate undershooting occurs when, by some combination of high output variability, low capital mobility, and high monetary accommodation to price movements, $\delta_{2}<0$. With $\delta_{1}>0$ and $\delta_{2}<0$, it is shown in Figure 2 that the slopes of the $D e_{t}=0$ curve and the saddle path are both positive. Following the increase in $\bar{m}$, the exchange rate depreciates to $E^{1}$ and continues to depreciate until the long run equilibrium is attained at $E^{2}$.

Since the intuition behind exchange rate undershooting caused by flexible output or imperfect capital mobility is familiar from Dornbusch (1976) and Frenkel and Rodriguez (1982), we will focus on accommodative monetary policy. Recall that accommodative monetary policy involves both accommodating prices and/or interest rates, so that $c_{2}$ and $c_{4}>0$. The increase in the domestic steady state money supply $(\bar{m})$ increases, because of the long run purchasing power parity assumption, the steady state exchange rate $(\overline{\mathrm{e}})$ and price ratio $(\bar{q})$. Assuming that both countries' policies are accommodative, and remembering that prices are predetermined, this causes the component of the domestic money supply that responds to prices to decrease and the foreign money supply to increase. If capital 
were perfectly mobile $\left(a_{5}=0\right)$ and output did not respond to relative prices $\left(d_{3}=0\right)$, undershooting would require $c_{2}+c_{4}>1$. In that case, an increase in the domestic steady state money supply causes a decrease in the money supply ratio $\left(m_{t}-m_{t}^{*}\right)$, which is consistent with asset market equilibrium only if the domestic interest rate exceeds the foreign interest rate. This in turn requires expected (and actual by perfect foresight) exchange rate depreciation, which implies undershooting. Once accommodative monetary policy is combined with variable output and imperfect capital mobility, the conditions for overshooting are greatiy relaxed. In particular, it is no longer necessary that either the money supply ratio decrease or that the domestic interest rate exceed the foreign interest rate to have undershooting.

Frenkel's (1983) proposal for accommodating interest rate differentials and offsetting exchange rates can now be evaluated. Accommodating interest rates acts to offset exchange rates and accommodate prices, which stabilizes the real exchange rate and output. The accommodation of prices inherent in accommodating interest rates increases the likelihood of undershooting. In addition, it is clear from (7) that accommodating interest rates causes the money supply to accommodate expected exchange rate depreciation. This lowers $\delta_{2}$ (in absolute value), decreasing the magnitude of either overshooting or undershooting. In this manner, the additional information contained in the interest rate is used to stabilize the exchange rate.

IV. Empirical Results: Germany, and Japan

The theory derived above relates exchange rate behavior to activist monetary policy, imperfect capital mobility, and variable output. In this section, using quarterly data since the advent of generalized floating in 
1973, the model is estimated for Germany and Japan. The empirical results are consistent with overshooting for the mark and undershooting for the yen.

The model is estimated by constrained maximum likelihood techniques, with the constraints on the parameters caused by the form of the structural equations, assumption of rational expectations, and the stability condition necessary to achieve a unique solution. The policy $\left(a_{8}-a_{13}\right)$ and structural $\left(a_{1}-a_{7}\right)$ coefficients are jointly estimated. Combined with the imposition of rational expectations, this satisfies several aspects of Lucas' (1976) critique of econometric policy evaluation. Using likelihood ratio tests, the constrained model cannot be rejected at standard significance levels for either country, al though the evidence is stronger for Japan than for Germany.

Estimation of the model first requires deriving the reduced form. Substituting equations as in the perfect foresight solution, and interpreting all variables as deviations from their long run equilibrium values, we obtain:

$$
\left[\begin{array}{l}
\hat{e}_{t+1} \\
q_{t+1}
\end{array}\right]=\left[\begin{array}{cc}
\delta_{1}+1 & \delta_{2} \\
\delta_{3} & \delta_{4}+1
\end{array}\right] \begin{aligned}
& e_{t} \\
& q_{t}
\end{aligned}+\left[\begin{array}{l}
u_{1 t} \\
u_{2 t}
\end{array}\right]
$$

(10) $y_{t}-y_{t}^{*}=\left(d_{3}-d_{4} \delta_{1}\right) e_{t}-\left(d_{3}-d_{4} \delta_{2}\right) q_{t}+u_{3 t}$

(11) $i_{t}-i_{t}^{\star}=\left(\delta_{1}-a_{5}\right) e_{t}+\left(\delta_{2}+a_{5}\right) a_{t}+u_{4 t}$

(12) $m_{t}=a_{8} e_{t}+a_{9} q_{t}+a_{10}\left(i_{t}-i_{t}^{*}\right)+u_{5 t}$

(13) $m_{t}^{*}=-a_{11} e_{t}-a_{12} q_{t}-a_{13}\left(i_{t}-i_{t}^{*}\right)+u_{6 t}$

where the $u$ 's are combinations of the $\varepsilon^{\prime} s$.

In order to derive the reduced form, the error terms must be finite moving average processes. We assume that they are generated by first order autoregressive processes, i.e., $u_{j t}=\alpha_{j} u_{j t-1}+\psi_{j t}, j=1, \ldots, 6$, where the 
Y's are serially uncorrelated. We then take the infinite moving average representation implicit in the above autoregressive process and truncate it appropriately. ${ }^{14}$ Assuming that expectations are determined rationally and solving by the method of undetermined coefficients, ${ }^{15}$ we obtain:

$$
\left[\begin{array}{l}
e_{t} \\
q_{t}
\end{array}\right]=A\left[\begin{array}{l}
e_{t-1} \\
q_{t-1}
\end{array}\right]+B(L)\left[\begin{array}{l}
v_{1 t} \\
v_{2 t}
\end{array}\right]
$$

where $A$ and $B$ are $2 \times 2$ matrices.

The model to be estimated consists of equations (10) - (14). The elements of $A$ and $B$ are non-Tinear combinations of the $\delta$ 's and the $\alpha^{\prime} s$. The V's are combinations of the $\Psi$ 's, written so as to make the zero lag coefficient matrix the identity matrix. ${ }^{16}$ By truncating the implicit moving average representation of the disturbances at third order for $u_{1}$ and fourth order for the others, a first order autoregressive fourth order moving average model is derived. Maximum likelihood estimates (conditional on the initial disturbances being set equal to zero) are obtained under the assumption that $\left(v_{1 t} v_{2} t^{u_{3}} t^{u_{4}} 4 t^{u_{5}} t^{u_{6 t}}\right)^{\prime}$ is multivariate normal.

As described above, the model is estimated for Germany and Japan, using quarterly data for 1973 (II) - (1981) (IV). ${ }^{17}$ We use the effective exchange rate (MERM) calculated by the International Monetary Fund. Real GNP (or GDP) is used to measure output, MI for the money supply, the GNP deflator for the price level, and representative three month money market rates for the interest rate. The foreign variables were constructed by taking weighted averages, with the weights taken from those used to construct the MERM rates. 18

The large number of structural and policy parameters (13) relative to the sample size (35) caused us to take several steps to limit the number of parameters to be estimated. One, described above, was to specify the error 
terms as first order autoregressions. Another was to estimate the money market equilibrium equation (1) by a single equation method, ${ }^{19}$ and then use the estimates from this regression as constants for the constrained maximum likelihood estimates. This enabled us to get estimates of the income elasticity and the interest rate semi-elasticity of the demand for money directly from data on income and interest rates, and to reduce the number of parameters to be estimated by maximum likelihood. 20

The maximum likelihood estimates of the structural $\left(a_{3}-a_{7}\right)$, policy $\left(a_{8}-a_{13}\right)$, and serial correlation $\left(\alpha_{1}-\alpha_{6}\right)$ parameters are given in Table 1 along with their asymtotic "t-ratios," the ratio of the coefficients to their standard errors computed from the inverse of the second derivative matrix of the likelihood function. Single equation estimates for $a_{1}$ and $a_{2}$, as well as parameter values for the reduced form coefficients implied by the estimates ( $c$ 's, $d^{\prime} s$ and $\delta^{\prime} s$ ) are also presented. For Japan, allowing the domestic and foreign money supplies to respond to the interest rate differential added virtually no explanatory power to the model; the results presented constrain $a_{10}$ and $a_{13}$ to equal zero. For Germany, on the other hand, allowing the money supplies to respond to the interest rate differential was quite important.

The most important aspect to the estimates is that $\delta_{2}$ is positive for Germany and negative for Japan, implying exchange rate overshooting for the mark and undershooting for the yen. ${ }^{21}$ Domestic $\left(a_{9}\right)$ and foreign $\left(a_{12}\right)$ monetary policy that accommodates prices, output $\left(d_{3}\right)$ that responds to relative price movements, and imperfect capital mobility $\left(a_{5}\right)$ all contribute towards undershooting for Japan. It is interesting to note that, while neither accommodative monetary policy, imperfect capital mobility, nor variable output were, by themselves, sufficient to produce undershooting, 
any two of the above three factors would suffice. The combination of all three, of course, strengthens the case for undershooting.

Exchange rate overshooting for Germany is caused by a number of factors, the most important of which being that German monetary policy strongly offsets price movements. Even though foreign monetary policy is accommodative, the combination $\left(c_{2}+c_{4}\right)$ is offsetting. In addition, the relative price elasticity of output $\left(d_{3}\right)$ is negative, which also contributes to overshooting. ${ }^{22}$ While capital mobility is imperfect, it is not sufficiently imperfect to outweigh these other factors and produce undershooting. 23

More support for the over and undershooting results comes from estimating a "semi-constrained" version of the model. In this version, $\delta_{1}$ and $\delta_{2}$ are estimated directly, rather than being implied by the structural and policy coefficients. All of the other coefficients of the model are estimated as in the constrained version above. This enables us to test the overshooting hypothesis directly by examining the sign and significance level of $\delta_{2}$. The results of this procedure support the results found above, with $\delta_{2}$ equaling $3.84(2.77)$ for Germany and $-.67(-1.81)$ for Japan, (asymptotic "t-ratios" are in parentheses). This indicates that not only does the mark exhibit overshooting and the yen undershooting, but that these results are significant. The values of $\delta_{1}$ are $.76(2.09)$ for Germany and $1.03(2.76)$ for Japan, indicating that the stability condition is sufficient to provide a unique solution. The structural, policy, and serial correlation coefficients (not reported) are very similar to those of the constrained model. Another piece of evidence in support of these results is found by examining the correlation between $e$ and $q$, which is positive (.22) for Japan and negative $(-.20)$ for Germany. This is 
consistent, as illustrated in Figures 1 and 2, both with undershooting for Japan and overshooting for Germany. 24

The empirical results illustrate a number of facets of the model. Imperfect capital mobility is strongly supported, with $a_{5}$ positive and significant for both countries. The coefficient on the real interest rate differential in the price adjustment equation $\left(a_{7}\right)$ is positive and significant for both countries. The coefficient on relative prices $\left(a_{6}\right)$ is positive for Japan and negative for Germany. For the single equation estimates, the income elasticities and interest rate semi-elasticities of the demand for money are of the expected signs and magnitudes. Finally, the correlations between the actual and estimated parameter values are quite high for Japan and lower for Germany.

More formal support for the model is provided by the likelihood ratio test. The model is compared to an "unconstrained" version, which imposes the same policy equations (12-13) and serial correlation structure as the "constrained" version described above, but does not impose the forms of the structural equations or the rational expectations restrictions. Using the likelihood ratio test, we cannot reject the constrained model at the 50 percent level for Japan or at the 10 percent level for Germany. ${ }^{25}$ This is in contrast to previous work for the current flexible exchange rate period, such as the models of Driskill and Sheffrin (1981), Glaessner (1982a), and Papel1 (1983), which are all rejected by the likelihood ratio or chisquared test. These results also compare favorably with the results of the likelihood ratio tests performed by Sargent (1978) and Taylor (1980) for closed economy models. They provide quite strong confirmation that the data does not contain too much evidence against the model.

The estimates reported above are conditional on the single equation 
estimates of the money demand parameters. We also estimated the model with all of the parameters estimated by maximum likelihood. These results are reported in Table 2. For Japan, the income elasticity of the demand for money $\left(a_{1}\right)$ decreases while the interest rate semi-elasticity $\left(a_{2}\right)$ does not change. Both parameters, however, become insignificant. There is little change in either the levels or significance of the other parameters and virtualiy no change in the $\delta^{\prime} s$. Neither the finding of undershooting nor the support of the estimates by the likelihood ratio test are affected. Both $a_{1}$ and $a_{2}$ increase and are significant for Germany. The other parameters change more, but not very much more, than they do for Japan and there is not much change in the $\delta^{\prime} s$. The finding of overshooting is not affected. The results of the likelihood ratio test are siightly worse. The constrained model can now not be rejected only at the 5 percent level, although it comes very close to not being rejected at the 10 percent leve1. 26 The support given to undershooting for Japan and overshooting for Germany by the semi-constrained model, reported above, is not affected because the estimates of the semi-constrained model do not involve the money demand parameters. In summary, the model with all of the parameters estimated by maximum likelihood gives virtually the same results as the model with $a_{1}$ and $a_{2}$ estimated by a single equation method.

The final estimates of the model are prompted by the fact that, for Japan, the serial correlation coefficients for the exchange rate $\left(\alpha_{1}\right)$ and price $\left(\alpha_{2}\right)$ equations are quite high, with $\alpha_{1}>1.27$ In order to attempt to reduce these, we estimate the model using first-differenced, rather than detrended, data. These results are reported in Table 3 with all of the parameters estimated by maximum likelihood. Although the levels and significance of the coefficients change considerably, the basic result, 
that the yen exhibits undershooting, is not affected. Estimation of the semi-constrained model using first-differenced data supports the finding of undershooting. ${ }^{28}$ The major improvement in the results comes from the estimation of the unconstrained model. Using the likelihood ratio test, the constrained model cannot be rejected at the 99 percent level. ${ }^{29}$ This is a very strong result, especially in contrast to the previous work cited above. 30

In addition to Germany and Japan, we attempted, without much success, to estimate the model for the United States and the United Kingdom. For the United States, although the coefficients were all of the expected sign and magnitude, very few were significant and the constrained model clearly failed the likelihood ratio test. For the United Kingdom, we were not even able to get the estimates to converge. One plausible explanation for these unsuccessful estimates is that, for the United States and the United Kingdom, the money supply rule changed during the period to become less accommodative. ${ }^{31}$ Compared to the change in monetary policy with the advent of the Thatcher government in May, 1979 in the United Kingdom or the change in the Federal Reserve Board's operating procedure in October, 1979 in the United States, no such dramatic change has occurred in Germany or Japan. We conclude by looking at the estimated policy parameters in the context of Frenkel's proposal, concentrating, since Japanese monetary policy was not responsive to interest rates, on the results for Germany. As described above, Frenkel's proposal is for monetary policy to accomrodate the interest rate differential and offset the exchange rate. While German monetary policy did accommodate interest rate movements, it also accommodated the exchange rate. In response to the combination of a positive interest rate differential and a depreciation of the Deutsche Mark 
(above the steady state), the German money supply increases (relative to trend). Frenkel's policy would have it stay constant or contract. In the context of our model, implementation of Frenkel's proposal for Germany would not alter the overshooting result. Exchange rate overshooting (or undershooting) is caused by the combination of capital mobility, output variability, and the responsiveness of monetary policy to prices (directly or through the interest rate differential). Since German monetary policy a) ready accommodates the interest rate differential, the overshooting result is invariant to whether or not, in addition, it offsets exchange rate movements.

v. Conclusions and Extensions

This paper has shown how, in the context of a model with slow price adjustment, imperfect capital mobility, variable output, and activist monetary policy can combine to produce exchange rate undershooting. It also provides evidence that, for the period of generalized floating since 1973, the mark exhibited overshooting and the yen exhibited undershooting. The estimation is quite successful, in contrast with most models of exchange rate determination for the same time period.

Possible extensions of the model are stimulated as much by our failures as our successes. While we were not able to produce satisfactory estimates for the United States or the United Kingdom, we can conjecture that this was caused, at least in part, by the dramatic shift towards less accommodative monetary policy in both countries. We intend to test for changes in the conduct of monetary policy by estimating the model over various sub-periods. Our model predicts that a less accommodative monetary policy will increase exchange rate overshooting or decrease undershooting. We hope to investigate whether the recent changes in exchange rate 
variability for the United States and the United Kingdom can be accounted for by changes in the conduct of monetary policy. 32 


\section{Footnotes}

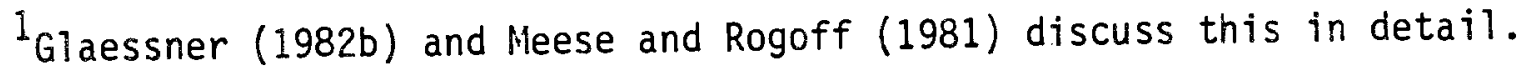

2 Mussa (1982) argues that the appropriate deflator for nominal balances is a weighted average of domestic and foreign goods price levels (denominated in domestic currency). This complicates but does not substantially affect the theoretical results. In addition, as shown by Flood (1981), if the income elasticity of the demand for money is equal to unity equation (1) would be unchanged under the Mussa formulation.

${ }^{3}$ Franke1 (1979) and Driskill and Sheffrin (1981) make the same assumption, which seems to be unavoidable without greatly complicating the model.

${ }^{4}$ It is necessary to equate the real interest rate semi-elasticities of output demand in the two countries $\left(a_{4}\right)$ in order for the model to be tractable. Allowing lags in the output equation produces another difference equation, which greatly complicates the model.

5 We use a flow capital mobility specification, while recognizing its deficiencies, to limit the model to a system of two first order difference equations. Modeling imperfect capital mobility as a stock adjustment process produces a much more complicated model, one which cannot be solved analytically. Allowing the current account to also depend on the interest rate differential does not affect the results.

$6_{\text {Mussa }}(1981 a, 1982)$ argues that a superior formulation to Dornbusch's price equation would have the rate of inflation equal the expected rate of change of the equilibrium price level, plus some proportion $(<1)$ of the difference between the equilibrium and the actual price level. As emphasized both by Mussa and by Obstfeld and Rogoff (1983), Dornbusch's price equation is inappropriate either when disturbances become anticipated long before they occur or when the long run equilibrium of the economy moves over time. Neither situation is considered in this paper.

7 Both Dornbusch's and Mussa's formulations assume that prices are predetermined. Assuming that prices are perfectly flexible, so that purchasing power parity holds at all times, does not accord with evidence from the 1970's. The recent work of Flood and Hodrick (1982), in which prices are neither flexible nor predetermined, provides another alternative for future empirical research.

8 Allowing the money supply to depend on contemporaneous, rather than past, values of the variables greatly simplifies the analysis. For the theory, assuming perfect foresight, this is equivalent to having the money supply depend on expectations of the current values of the variables, conditional on information available at the end of the previous period.

9 Our definition of accommodative, while clear with regard to domestic price moments, may cause some semantic difficulties in considering foreign price movements. In some of the discussion of supply shocks, an increase in the foreign price level (price of the imported good) would cause the 
domestic price index to increase. In that context, accommodative monetary policy implies that the domestic money supply increases when the foreign price level increases. In our context, accommodative monetary policy implies that the domestic money supply decreases when the foreign price
level increases.

${ }^{10}$ The only tractable way to accomplish this is to assume that the domestic and foreign money supplies respond identically to price movements, an assumption that does not seem tenable.

$11_{\text {By }}$ "the money supply" we mean the sum of the coefficients of the domestic and foreign money supplies. The possibility that $\delta<0$ which can lead to a non-unique solution, will be considered in a subsequent paper.

${ }^{12}$ The over- and undershooting results are invariant to the slope of the $\mathrm{Dq}_{t}=0$ curve, which is drawn to be positive and less than unity solely for ease of illustration. With Dornbusch's price adjustment formulation $\left(a_{2}=0\right)$, the slope of the $\mathrm{Dq}=0$ schedule would be unity $\left(\delta_{3}=-\delta_{4}\right)$, and the figures would replicate ( $w i$ th the axes reversed) those found in 4 Frenkel and Rodriguez (1982).

13 While these diagrams are more familiar in continuous time, Mussa (1982) uses them in a discrete time model. We present the theoretical results in discrete time for the purpose of comparison with the empirical
work.

14 rather than number of parameters to be estimated.

${ }^{15}$ The model could, of course, have been solved by other methods. The derivation of (14) is straightforward but lengthy, and therefore not presented.

16 We do not impose the cross error constraints on the $v$ 's. Otherwise, there would be cross correlation among the errors and the estimates would be inconsistent.

${ }^{17}$ The end of our sample period was caused by data availability when the paper was first written.

18

The interest rates used for the estimation were representative money market rates, taken from World Financial Markets. All other data were taken from International Financial Statistics. The real output, price level, and money supply data were seasonally adjusted. In order to achieve stationarity, all variables, after taking logarithms (except for the interest rate), were detrended by regression on a constant and linear time trend. The countries used for constructing the foreign variables were Canada, France, Germany, Italy, Japan, the United Kingdom, and the United States, with the weights proportional to the MERM weights.

${ }^{19}$ We used the ARI procedure of TSP, which provides efficient estimates of an equation whose disturbances display first order serial correlation. 
${ }^{20}$ This procedure raises two questions regarding consistency of the estimates. On one hand, estimating the money demand coefficients by a single equation method may introduce inconsistency into the model. On the other hand, if these parameters are still inconsistently estimated when estimated by maximum likelihood, then the inconsistency would be spread throughout the model. Another problem with our procedure is that, because for the maximum likei ihood procedure it is assumed that $a_{1}$ and $a_{2}$ are estimated without error, the standard errors of the other variables are biased downward. We report estimates where all of the parameters are estimated by maximum likelihood below.

${ }^{21}$ Dornbusch's concept of overshooting describes the behavior of the exchange rate after a permanent increase in the money supply while, for the empirical work, all disturbances are temporary. In this context, overshooting is interpreted as the existence of estimated parameter values such that, in the deterministic model, a permanent increase in the money supply would cause the exchange rate to overshoot.

${ }^{22}$ Both $d_{3}$ and $d_{4}$ are negative for Germany because $a_{4}$, the real interest rate semi-elasticity of output demand, is negative. This, of course, does not accord with the theory. In an earlier version of this paper, we estimated the model with $a_{4}$ constrained to equal zero. In that version, $a_{3}$ was negative. This issue is explored at greater length, but no more satisfactority, in Papel1 (1983).

${ }^{23}$ In Papel1 (1983), we estimate a similar model (with perfect capital mobility) for the Deutsche Mark/Dollar exchange rate. While American monetary policy is accommodative of prices, German monetary policy is sufficiently offsetting to produce overshooting. These results are consistent with the findings for Germany in this paper.

${ }^{24}$ The value of $\delta_{3}$ implied by the estimates was quite close to zero for both countries. This could be illustrated with a vertical $\mathrm{Dq}_{t}=0$ schedule in the figures.

${ }^{25}$ Let $L(u)$ be the $\log$ of the likelinood function for the unconstrained model, $L(c)$ the $\log$ of the likelihood function for the constrained model, $u$ the number of parameters estimated for the unconstrained model, and $c$ the number of parameters estimated for the constrained model. Then $2[L(u)-L(c)]$ is distributed chi-squared $(u-c)$. There are 22 parameters in the unconstrained model for Germany and 20 for Japan ( The unconstrained log likelihood for Japan is 575.804 : thus $2[L(u)=[(c)]$ $=3.682$. The unconstrained log likelihood for Germany is 638.487 : $2[L(u)-L(c)]=7.348$. With $u-c=5$ for both countries, the constrained model cannot be rejected at the 50 percent level for Japan or at the 10 percent level for Germany.

26 Using the notation in footnote 25 , with $u-c=3$ for both countries, $2[L(u)-L(c)]$ equals 2.278 for Japan and 6.462 for Germany. The 10 percent marginal significance level is 6.251 .

27 Allowing the third order moving average process $u_{1}$ to be represented by a second order autoregression or a third order movthg average, instead of the first order autoregression adopted in the paper, does not 
affect this result.

${ }^{28} \delta_{1}$ equals $11.35(93.21)$ and $\delta_{2}$ equals $-11.69(-76.12)$. Asymtotic "t-ratios" are in parentheses.

${ }^{29}$ The log likelihood of the unconstrained model is 518.928 , so that $2[L(u)-L(c)]=.098$.

30 We

We experimented with estimating a model using first-differenced data for Germany, even though the serial correlation coefficients using detrended data were not overly high. The precision of the estimates of the parameters decreased, and the constrained model was rejected when compared to the unconstrained model by the likelihood ratio test.

${ }^{31}$ For the United Kingdom, other changes during the period include the relaxation of capital controls and exploitation of North Sea oil. Haache and Townend (1981), using single equation estimation techniques, are unsuccessful at modeling steriling's effective exchange rate for 1972-80.

32 A preliminary attempt to accomplish this, using considerations of exchange risk not present in this paper, is made for the United States in Papel1 (1983b). 


\section{References}

Dornbusch, R. (1976). "Expectations and Exchange Rate Dynamics," Journal of Political Economy, 85, December, 1161-1176.

Driski11, R. and S. Sheffrin (1981). "On the Mark: Comment," American Economic Review, 71, December, 1068-1074.

Flood, R. (1981). "Explanations of Exchange-Rate Volatility and Other Empirical Regularities in Some Popular Models of the Foreign Exchange Market," in K. Brunner and A. Meltser (eds.), Carnegie-Rochester Conference Series, Vol. 15.

and R. Hodrick (1982). "Optimal Price and Inventory Adjustment in an Open-Economy Model of the Business Cycle," unpublished, Federal Reserve Board.

Franke1, J. (1979). "On the Mark: A Theory of Floating Exchange Rates Based on Real Interest Differentials," American Economic Review, 69, September, $610-22$.

Frenke1, J. (1983). "Monetary Policy: Domestic Targets and International Constraints," American Economic Review, 73, May, 48-53.

and C.A. Rodriguez (1982). "Exchange Rate Dynamics and the Overshooting Hypothesis," International Monetary Fund Staff Papers, March.

Glaessner, T. (1982a). "Formulation and Estimation of a Dynamic Model of Exchange Rate Determination: An Application of General Method of Moments Techniques," International Finance Discussion Paper No. 208 , Federal Reserve Board.

(1982b). "Theoretical and Empirical Essays on the Determination of Spot and Forward Exchange Rates," Unpublished Ph.D. dissertation, University of Virginia.

Haache, G. and J. Townend (1981). "Exchange Rates and Honetary Policy: Modeling Sterling's. Effective Exchange Rate, 1972-80," in Eltis, W.A. and P.J.N. Sinclair. The Money Supply and the Exchange Rate, (Oxford, Clarendon Press, 1981).

Lucas, R. (1976). "Econometric Policy Evaluation: A Critique," in K. Brunner and A. Meltzer (eds.), The Phillips Curve and Labor Markets.

Meese, R. and K. Rogoff (1981). "Empirical Exchange Rate Models of the Seventies: Do They Fit Out of Sample?" International Finance Discussion Paper No. 184, Federal Reserve Board.

Mussa, M. (1981a). "Sticky Prices and Disequilibrium Adjustment in a Rational Expectations Models of the Inflationary Process, American Economic Review, 71, December, 1020-1027. 
(1981b). "The Role of Official Intervention," Group of Thirty Occasional Paper No. 6, New York.

(1982). "A Model of Exchange Rate Dynamics," Journal of Political Economy, 90, February, 74-104.

Obstfeld, M. and K. Rogoff (1983). "Exchange Rate Dynamics with Sluggish Prices Under Alternative Price Adjustment Rules," International Finance Discussion Paper No. 223, Federal Reserve Board, May.

Papel1, D. (1983a). "Activist Monetary Policy and Exchange Rate Overshooting: The Deutsche Mark/Dollar Rate," National Bureau of Economic Research Working Paper No. 1195, August.

(1983b). "Monetarist Monetary Policy, Exchange Risk, and Exchange Rate Variability," unpublished, University of Florida, July.

Sargent, T. (1978). "Estimation of Dynamic Labor Demand Schedules Under Rational Expectations," Journal of Political Economy, 86, December, 1009-1044.

Taylor, J. (1980). "Output and Price Stability: An International Comparison," Journal of Economic Dynamics and Control, February, 109-132. 
Table 1

\section{Japan Germany Constrained Maximum Likel ihood Estimates}

\begin{tabular}{|c|c|c|c|c|}
\hline Parameter & Estimate & $\begin{array}{l}\text { Asymptotic } \\
\text { "t-ratio" }\end{array}$ & Estimate & $\begin{array}{l}\text { Asymptotic } \\
\text { "t-ratio" }\end{array}$ \\
\hline \multirow[t]{3}{*}{$\begin{array}{l}a_{3} \\
a_{4} \\
a_{5} \\
a_{6} \\
a_{7} \\
a_{8} \\
a_{9}^{8} \\
a_{10} \\
a_{11} \\
a_{12} \\
a_{13} \\
a_{1} \\
a_{2} \\
a_{3} \\
a_{4} \\
a_{5} \\
\alpha_{6}\end{array}$} & $\begin{array}{r}.17 \\
.53 \\
.80 \\
.07 \\
.24 \\
.02 \\
.50 \\
.13 \\
-.13 \\
.15 \\
1.05 \\
.77 \\
.60 \\
.33 \\
.75 \\
.42\end{array}$ & $\begin{array}{r}.96 \\
1.21 \\
2.22 \\
1.96 \\
1.93 \\
.30 \\
6.94 \\
-1.74 \\
1.37 \\
8.87 \\
9.70 \\
6.33 \\
2.62 \\
11.03 \\
3.42\end{array}$ & $\begin{array}{r}.03 \\
-.74 \\
.75 \\
-.04 \\
.07 \\
.27 \\
-6.74 \\
2.30 \\
-.17 \\
6.06 \\
-1.86 \\
.48 \\
-.12 \\
.65 \\
.70 \\
.80 \\
.67\end{array}$ & $\begin{array}{r}.07 \\
-1.42 \\
2.91 \\
-1.52 \\
2.03 \\
.67 \\
-2.65 \\
3.50 \\
-.36 \\
3.16 \\
-3.03 \\
4.05 \\
-2.64 \\
6.45 \\
19.80 \\
22.74 \\
16.60\end{array}$ \\
\hline & \multicolumn{4}{|c|}{ Single Equation Estimates } \\
\hline & Estimate & t Statistic & Estimate & $t$ statistic \\
\hline $\begin{array}{c}a_{1} \\
-a_{2}\end{array}$ & $\begin{array}{r}.82 \\
-.67\end{array}$ & $\begin{array}{r}5.63 \\
-2.91\end{array}$ & $\begin{array}{r}.53 \\
-.43\end{array}$ & $\begin{array}{r}3.37 \\
-1.81\end{array}$ \\
\hline
\end{tabular}

Parameter Values Implied by the Estimates

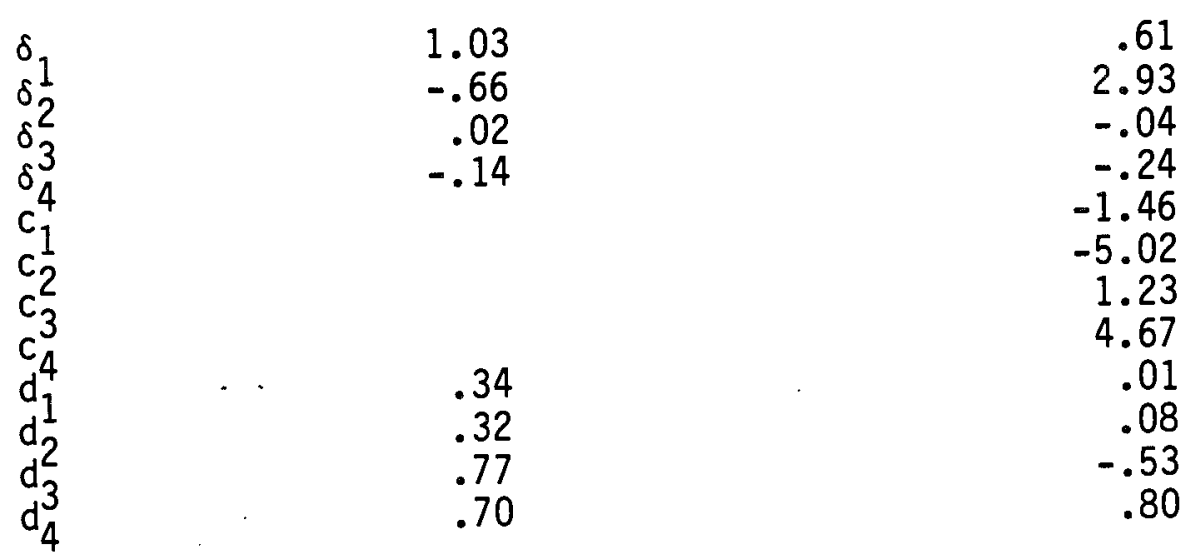

Correlation Between Actual and Estimated Values

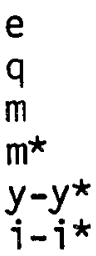

$$
\begin{aligned}
& .88 \\
& .97 \\
& .91 \\
& .77 \\
& .77 \\
& .82
\end{aligned}
$$


Table 2

Constrained Maximum Likelihood $\frac{\text { Germany }}{\text { Estimates }}$

$\begin{array}{ccccc}\text { Parameter } & \text { Estimate } & \begin{array}{c}\text { Asymptotic } \\ \text { "t-ratio" }\end{array} & \text { Estimate } & \begin{array}{c}\text { Asymptotic } \\ \text { "t-ratio" }\end{array} \\ a_{1} & .26 & .38 & 3.36 & 3.94 \\ a_{2} & .66 & 1.16 & 2.69 & 8.45 \\ a_{3} & .17 & 1.00 & .05 & .55 \\ a_{4} & .56 & 1.29 & -.74 & -6.82 \\ a_{5} & .80 & 2.15 & .85 & 3.88 \\ a_{6} & .08 & 2.12 & -.03 & -1.48 \\ a_{7} & .26 & 2.14 & .06 & 2.44 \\ a_{8} & -.01 & -.05 & .20 & .92 \\ a_{9} & .66 & 4.05 & -4.12 & -1.66 \\ a_{10} & & & 1.19 & 1.38 \\ a_{11} & -.13 & -1.80 & .09 & .23 \\ a_{12} & .17 & 1.54 & 4.12 & 2.60 \\ a_{13} & & & -1.07 & -2.11 \\ \alpha_{1} & 1.06 & 8.95 & .47 & 5.44 \\ a_{2} & .76 & 9.19 & -.11 & -2.48 \\ a_{3} & .60 & 6.17 & .64 & 9.87 \\ a_{4} & .33 & 2.63 & .69 & 19.13 \\ \alpha_{5} & .74 & 10.15 & .84 & 13.85 \\ \alpha_{6} & .43 & 3.35 & .63 & 9.92\end{array}$

Parameter Values Implied by the Estimates

$\delta_{1}$
$\delta_{2}^{1}$
$\delta_{3}^{2}$
$\delta_{4}$
$c_{1}^{1}$
$c_{2}^{2}$
$c_{3}$
$c_{4}$
$d_{1}$
$d_{2}^{2}$
$d_{3}^{3}$
$d_{4}$

1.03

$-.67$

.03

$-.15$

.60

3.15

$-.02$

$-.21$

$-.81$

$-3.11$

1.00

.39

.35

.84

.76

3.21

.02

.06

$-.59$

$-.78$

Correlation Between Actual and Estimated Values

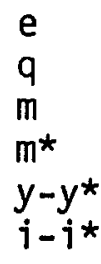

.88

.97

.91

.77

.77

.82

.80

.57

.95

.68

.84

.78

$\underline{\text { Log Likelihood }}$

574.665

635.256 
Table 3

Estimates with First-Differenced Data

Constrained Maximum Likel ihood Estimates

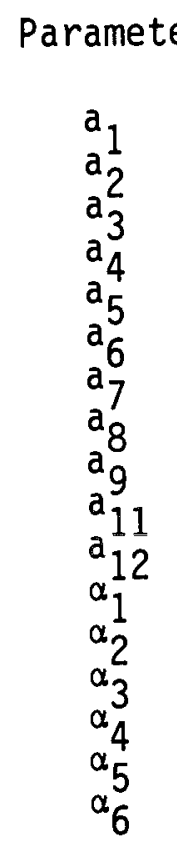

Estimate

Asymptotic

2.79

7.11

1.70

$-.95$

4.70

.21

.44

3.33

$-1.85$

$-.60$

$-.71$

.48

$-.29$

.45

.08

.49

.69

"t-ratio"

Parameter Values Implied by the Estimates

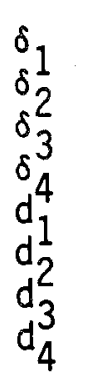

5.15

$-4.80$

.01

$-.28$

4.07

.79

$-6.63$

$-1.70$

Correlation Between Actual and Estimated Values

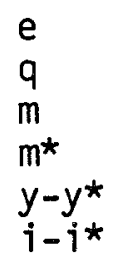

.52

.66

.13

.10

.27

.49

Log Likelihood

518.879 


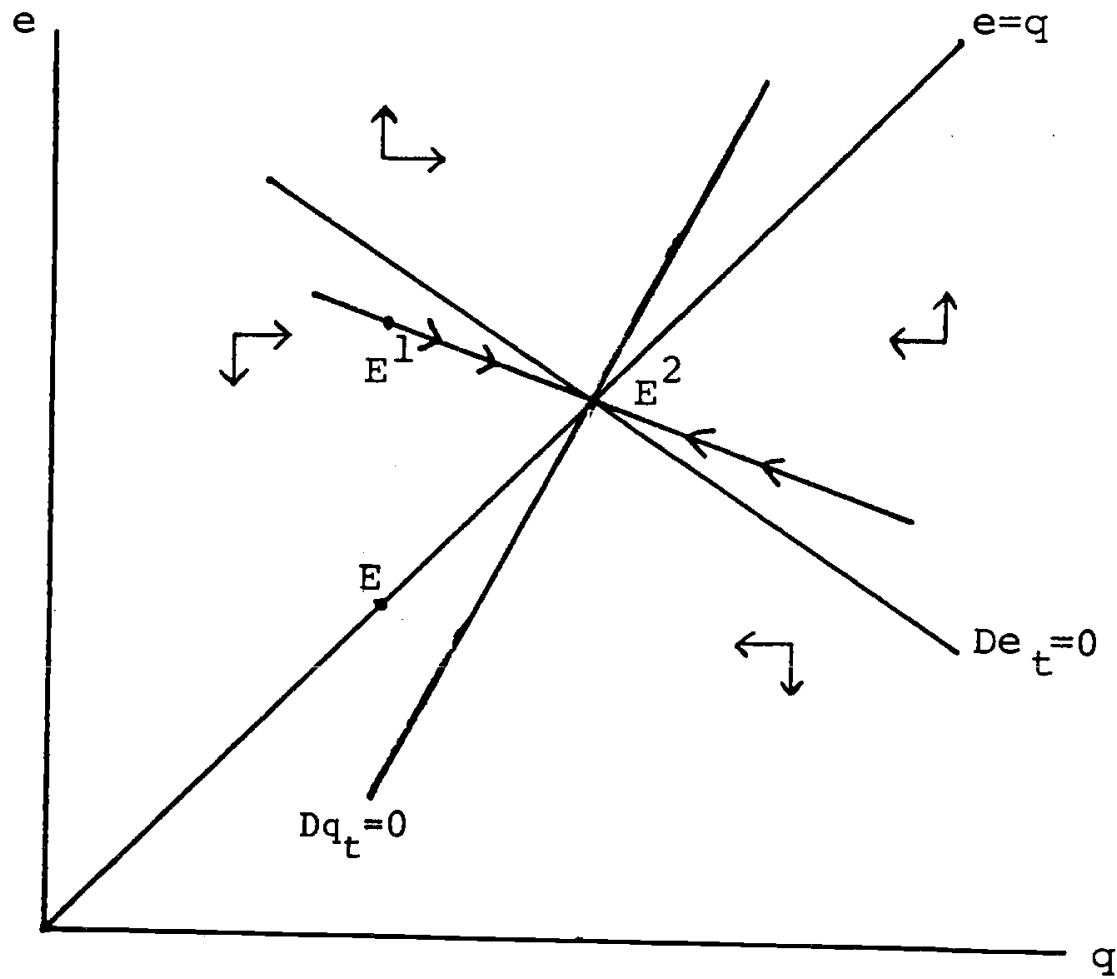

Figure 1

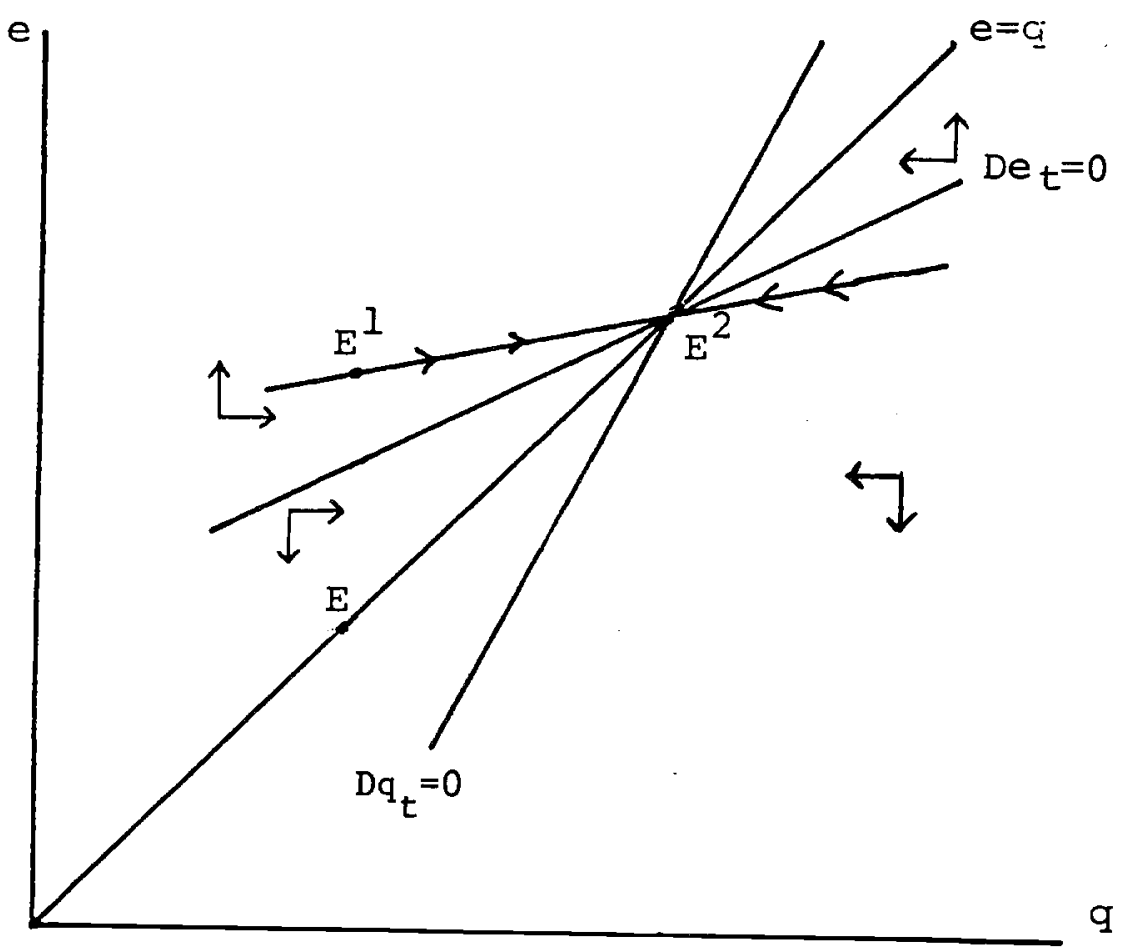

Figure 2 